\title{
Influence of Chemical Treatment on Tensile and Flexural Properties of Sansevieria Cylindrica Polyester Composites
}

\author{
C.Bennet, N.Rajini, J.T.Winowlin Jappes
}

\begin{abstract}
The sansevieria cylindrica polyester composite slabs are made by compression molding technique using fibres treated with sodium hydroxide $(\mathrm{NaOH})$, silane, calcium hydroxide $(\mathrm{Ca}(\mathrm{OH}) 2)$ and potassium permanganate $(\mathrm{KMnO4})$ for optimum fibre length, optimum weight percentage and optimum curing temperature ( $40 \mathrm{~mm}, 40 \% \mathrm{wt}, 60^{\circ} \mathrm{C}$ ) and their tensile properties have been studied. The inclusion of sansevieria cylindrica fibre as reinforcement into polyester matrix improves the flexural and tensile strength till a certain weight percentage, then it decreases drastically by further addition of fibre. The main problem in natural fibre is water uptake which damages the fibre and thereby the strength is reduced. To improve the performance, surface modification of fibres with various chemical treatments is performed and it enhanced the properties to a greater extent. $\mathrm{Ca}(\mathrm{OH}) 2$ treated composites showed higher tensile strength whereas silane treated composites showed lower tensile strength. $\mathrm{KMnO} 4$ treated composites showed higher flexural strength whereas silane treated composites showed lower flexural strength.
\end{abstract}

Keywords: Chemical treatment, Compression molding technique,Curing temperature, Sansevieria Cylindrica fibre

\section{INTRODUCTION}

$\mathrm{N}$ atural fibres have attracted the international research fraternity over the past few years. In general, natural fibre reinforcement gives poor compatibility with polymer matrix because of the surface which is waxy in nature. Moreover, the chemical treatment on the natural fibres cleans and modifies the fibre surface, moisture absorption is prevented and the surface roughness is increased. Hence, surface modification and chemical treatment of natural fibres are needed to improve the strength and compatibility. A better interlocking can be offered by the pre treatments of the fibre materials. Sisal fibre reinforced epoxy composite treated with $\mathrm{NaOH}$ and Silane enhances the adhesion between the fibre and the matrix. Silane treatment is the most effective in reducing moisture uptake of fibres in humid environments, as reported by Bisanda et al. [1]. The development of bio composites reinforced with epoxy matrix was carried out by Girisha et al.

Revised Manuscript Received on December 15, 2019.

* Correspondence Author

C.Bennet*, Department of Mechancical Engineering, Kalasalingam Academy of Research and Education, Krishnankoil-626126, India. Email: benutha24@rediffmail.com

N.Rajini, Department of Mechancical Engineering, Kalasalingam Academy of Research and Education, Krishnankoil-626126, India. Email: rajiniklu@gmail.com

J.T.Winowlin Jappes, Department of Mechancical Engineering, Kalasalingam Academy of Research and Education, Krishnankoil-626126, India. Email: winowlin@yahoo.com
[2] where arecanut fruit husk fibres and tamarind fruit fibres were reinforced with epoxy matrix and its mechanical properties had been performed with varying fibre weight percentages from 10 to $50 \%$. The studies also carried out for $\mathrm{NaOH}$ treated fibres where the results showed a change in the mechanical properties when compared with untreated fibre The investigation on mechanical properties of unidirectional Roystonea regia natural fibre rereinforced epoxy composites was carried out by Govardhan Goud et al. [3]. Alkali treated fibre showed enhanced tensile and flexural strength due to better fibre matrix interface. The use of silane or other coupling agents reduces this effect as proved by Hill et al. [4]. Alkali treatment and morphological characterization studies on banana fibre reported by Julio César Mejía Osorio et al. [5] revealed that the treated fibres surface was rougher than untreated fibres. Kabir et al. [6] studied the surface modifications of natural fibres to increase the strength of the composites. The fibres were treated in order to have better interaction with the matrix which was evaluated by Laly.A.Pothan et al. [7]. Various silanes and alkali were used to change the fibre surface and their effect was analyzed by Laly.A.Pothan et al. [8]. Leonard et al. [9] analyzed the effect of alkalization of natural fibres. An analysis on the influence of chemical modification on natural fibre reinforced composites was done by Rakesh Kumar et al. [10] and reported that the adhesion between the hydrophilic fibre and hydrophobic matrix increased by the chemical modifications. Sreenivasan et al. [11] discussed the effect of surface modification of fibre on tensile and flexural properties of short sansevieria cylindrica composites. A complete review study on pretreatments of the natural fibre has been done by Susheel Kalia et al. [12] and reported that because of the surface treatments, the fibre surface are cleaned, the surface are chemically modified, the moisture absorption process is prevented and the surface roughness is increased.

Many researchers have discussed the influence of chemical treatment on tensile properties of natural fibre composites fabricated under room curing temperature. But studies on the influence of chemical treatment on tensile and flexural properties of natural fibre composites fabricated under higher curing temperature are very limited. Hence an attempt is made to study the same using sansevieria cylindrica fibre reinforced composites. 


\section{EXPERIMENTAL}

\section{A. Material used}

Sansevieria Cylindrca fibres also known as marulkodi or uruvanthandu in local language in the southern part of Tamilnadu are collected from the farms near Cumbum valley and are used as reinforcement. Unsaturated isophthalic polyester (USP) resin supplied by Vasavibala resins, Chennai, India is used as the matrix material. Accelerator is Cobalt Naphthanate and catalyst is Methyl Ethyl Ketone Peroxide (MEKP).

\section{B. Fabrication of composite}

The sanseveiria cylindrica fibre is cut approximately into optimum fibre length of $40 \mathrm{~mm}$. The unsaturated polyester resin grade VBR 4303 is used as a matrix. Fibres are arranged in random orientation. At first, polyester is mixed with catalyst and accelerator to the required proportion and poured in the mould made of EN90 steel with the dimensions of $180 \times 160 \times 3 \mathrm{~mm}$. After placing the mould in the machine, it is compressed by applying curing pressure of $15 \mathrm{Mpa}$ and optimum curing temperature $\left(60^{\circ} \mathrm{C}\right)$. After chemical treatment, the treated fibres are dried at room temperature for 24 hours.

\section{TESTING OF COMPOSITES}

\section{A. Tensile test}

The tensile test is generally performed by Universal Testing Machine (Instron series - 3382) with the capacity-3T. As per ASTM D 3039, tests are done. $3 \mathrm{~mm}$ thickness is maintained. The tension test is performed on all the five samples and the average is taken.

\section{B. Flexural test}

The flexural test measures the force required to bend a beam under three point loading conditions. $50 \mathrm{~mm}$ span is taken and $2 \mathrm{~mm} / \mathrm{min}$ of cross head speed is maintained. As per ASTM D 790, flexural tests are performed. For each test, five samples are taken and the results are averaged.

\section{Scanning Electron Microscope (SEM)}

SEM studies are carried out to find the failure mechanism at the broken surface of the composites. The fibre surface is examined using the instrument Carl zeiss Pvt.Ltd, EVO MA15 model, UK.

\section{RESULT AND DISCUSSIONS}

\section{A. Tensile strength}

The influence of chemical treatment on tensile strength and modulus of treated sansevieria cylindrica fibre reinforced polyester composites fabricated with higher curing temperature is shown in figure 1.Sansevieria cylindrica fibre is subjected to different chemical treatments like alkalization, permanganate treatment, and silane to modify the surface and to remove the wax, hemicelluloses etc to make it a rough topography. Among the chemically treated fibre composites fabricated with optimum conditions, $\mathrm{Ca}(\mathrm{OH})_{2}$ treated composites show higher tensile strength of $55 \mathrm{MPa}$ compared to all other treatments followed by $\mathrm{KMnO}_{4}$ treated composites with a tensile strength of $50 \mathrm{MPa}$. This may be due to improved polymerized network between the fibre and matrix holding them together compared with other treatments. However, the tensile strength of all the treated composites cured at $60^{\circ} \mathrm{C}$ is found to decrease compared to untreated one. This may be due to the removal of hemicelluloses and other cementing material. The amorphous cellulose content of the fibre is directly exposed to higher curing temperature which could have caused damage to the fibre core leading to its breakage and hence, affects its load carrying capacity.As a result, better bonding between the fibre surface and matrix may not be effected and moreover high resin flow may occur which could have affected the bonding phenomena. Hence, the tensile strength could have shown a decline value compared with untreated one.It may be concluded that the effect of chemical treatment on composites fabricated with higher curing temperature fails to enhance the tensile strength of the composites compared with untreated one.

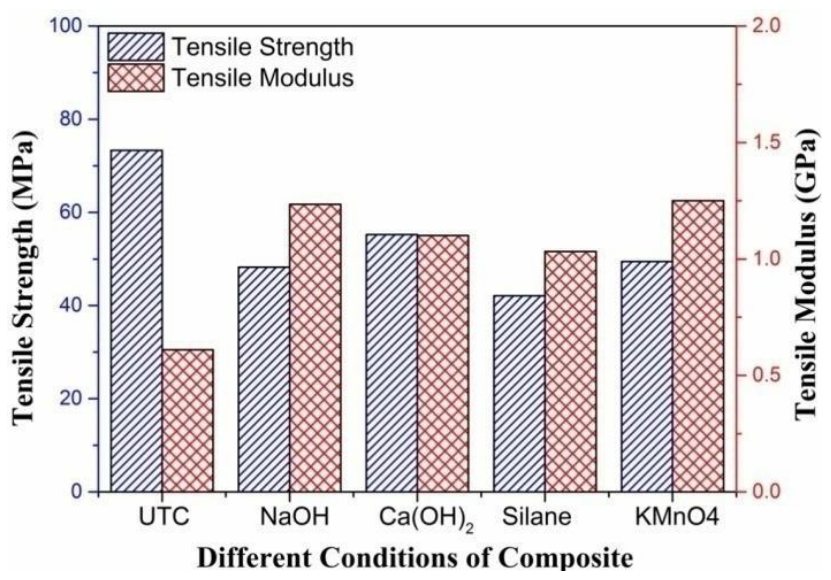

Fig. 1. Influence of chemical treatment on tensile strength and modulus of treated sansevieria cylindrica fibre $\left(40 \mathrm{~mm}, 40 \% \mathrm{wt}, 60^{\circ} \mathrm{C}\right.$ ) reinforced polyester composites
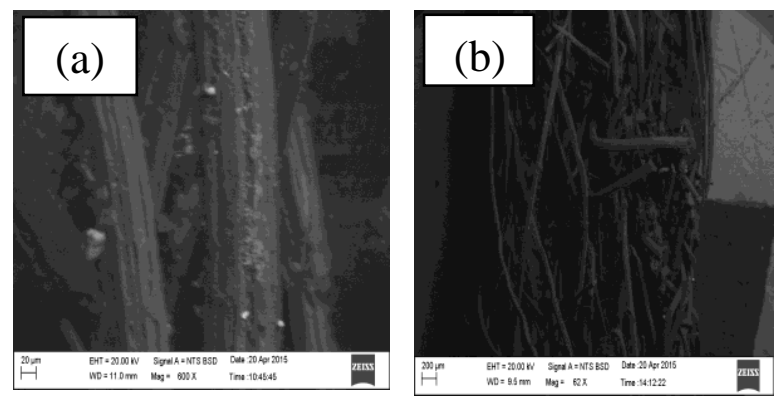

Fig. 2. (a),(b) SEM studies of $\mathrm{Ca}(\mathrm{OH})_{2}$ treated specimen on tensile strength of treated sansevieria cylindrica fibre $\left(40 \mathrm{~mm}, 40 \% \mathrm{wt}, 60^{\circ} \mathrm{C}\right)$ reinforced polyester composites 

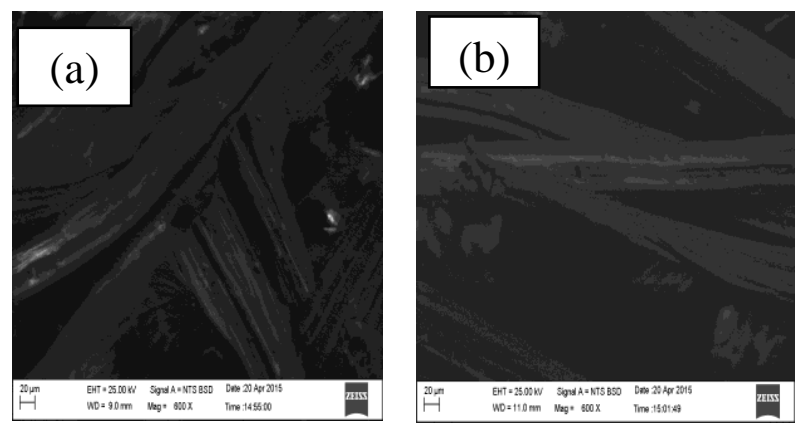

Fig. 3. (a),(b) SEM studies of silane treated specimen on tensile strength of treated sansevieria cylindrica fibre $(40 \mathrm{~mm}$, $40 \% \mathrm{wt}, 60^{\circ} \mathrm{C}$ ) reinforced polyester composites

\section{B. Flexural strength}

The influence of chemical treatment on flexural strength of treated sansevieria cylindrica fibre reinforced polyester composites fabricated with higher curing temperature is shown in Figure 4.

Among the treated composites, $\mathrm{KMnO}_{4}$ and $\mathrm{NaOH}$ treated composites possess high flexural strength compared to all other treatments. Hence, a better interfacial bonding exists between the fibre and matrix. Sansevieria cylindrica fibre composites make plastic deformation effect on brittle polyester matrix. This may be due to the increase in lignin content $(3.8 \%$ to $6.33 \%)$ and decrease in wax content $(0.09 \%$ to $0.03 \%)$ after the treatment with potassium permanganate which increases the rigidity and stiffness of the composite compared with other treatments. It leads to only a slight increase in lignin content.

Fig. 4. Influence of chemical treatment on flexural

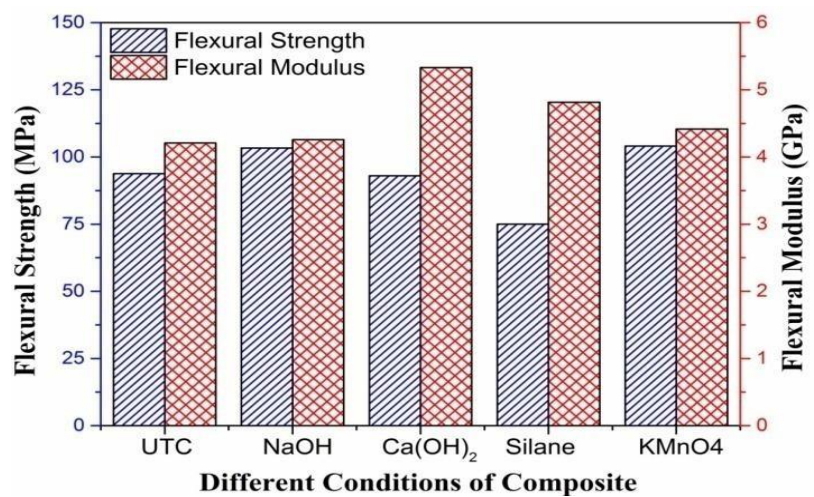

strength and modulus of treated sansevieria cylindrica fibre $\left(40 \mathrm{~mm}, 40 \% \mathrm{wt}, \mathbf{6 0}^{\circ} \mathrm{C}\right)$ reinforced polyester composites

\section{CONCLUSION}

The untreated sansevieria cylindrica fibre reinforced composites fabricated with optimum conditions exhibit higher tensile strength of $73 \mathrm{MPa}$. Among the treated composites, $\mathrm{Ca}(\mathrm{OH})_{2}$ treated shows higher tensile strength of $55 \mathrm{MPa}$. Higher tensile modulus is exhibited by $\mathrm{KMnO} 4$ treated composites. The untreated sansevieria cylindrica fibre reinforced composites fabricated with optimum conditions exhibit higher flexural strength for $\mathrm{KMnO}_{4}$ treated composites which have shown an enhanced strength of 104 MPa among all treated and untreated composites.

\section{ACKNOWLEDGMENT}

The authors express gratitude to the centre for composite materials, Kalasalingam Academy of Research and Education, Krishnankoil for providing necessary help to carry out this work.

\section{REFERENCES}

1. ETN.Bisanda and MP.Ansell," The effect of silane treatment on the mechanical and physical properties of sisal-epoxy composites", Composites Science and Technology, Vol. 41 (2), 1991, 165-178.

2. C.Girisha, Sanjeeva Murthy, Gunti Ranga srinivas and S.Manu, "Mechanical Performance Of Natural Fiber-Reinforced EpoxyHybrid Composites", International Journal of Research and Applications, Vol.2 (5), 2012, 615-619.

3. Govardhan Goud and RN.Rao, "Effect of fiber content and alkali treatment on mechanical properties of roystonea regia-reinforced epoxy partially biodegradable composites", Journal of Bulletin Material Science, Vol.34 (4), 2011, 1575-1581.

4. CAS.Hill and HPS.Abdul Khali, "Effect of fiber treatments on mechanical properties of coir or oil palm fiber reinforced polyester composites", Journal of Applied Polymer Science, Vol.78 (9), 2000,1685-1697.

5. Julio César Mejía Osorio, Rodolfo Rodríguez Baracaldo and Jhon Jairo Olaya Florez, "The influence of alkali treatment on banana fibre's mechanical properties", Ingeniería E Investigación, Vol.32 (1), 2012, 83-87.

6. MM.Kabir, H.Wang, KT.Lau and F.Cardona, "Chemical treatments on plant-based natural fiber reinforced polymer composites: an overview", Composites Part B: Engineering, Vol.43 (7), 2012, 2883-2892.

7. Laly A Pothan, CN.George, M.Jacob, and S.Thomas, "Effect of chemical modification on the mechanical and electrical properties of banana fiber polyester composites", Journal of Composite Materials, Vol.41 (19), 2007, 2371-2386.

8. Laly A Pothan, Jayamol George and Sabu Thomas, "Effect of fiber surface treatments on the fiber-matrix interaction in banana fiber reinforced polyester composite", Composite Interfaces, Vol. 9 (4), 2002, 335-353.

9. Y.Leonard , Mwaikambo and P.Martin , "Chemical modification of hemp, sisal, jute, and kapok fibers by alkalization", Journal of Applied Polymer Science, Vol. 84, 2002, 2222-2234.

10. Rakesh Kumar, Sangeeta Obrai and Aparna Sharma, "Chemical modifications of natural fiber for composite material", Pelagia Research Library Der ChemicaSinica, Vol. 2 (4), 2011, 219-228.

11. VS.Sreenivasan,S. Somasundaram, D.Ravindran, V.Manikandan and R.Narayanasamy , "Microstructural, physico-chemical and mechanical characterization of sansevieria cylindrica fibers - an exploratory investigation", Materials and Design, Vol. 32 (1), 2011, 453-461.

12. BS. Susheel Kalia, Kaith and Inderjeet Kaur, "Pretreatments of natural fibers and their application as reinforcing material in polymer composites - A review", Polymer Engineering \& Science, Vol.49 (7), 2009, 1253-1272.

\section{AUTHORS PROFILE}

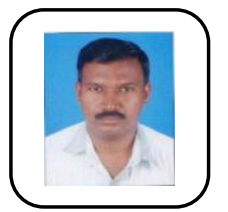

Dr.C.Bennet is an Associate Professor in the Department of Mechanical Engineering, Kalasalingam Academy of Research and Education, Krishnankoil, Tamilnadu, India. His current area of research includes polymer matrix composites, characterization and its studies. He has published a number of papers in journal of national/international repute and presented a number of papers in various conferences/symposia in India and abroad. He is presently guiding a number of master/doctoral research scholars. Dr.C.Bennet is the corresponding author and can be contacted at: benutha24@rediffmail.com 


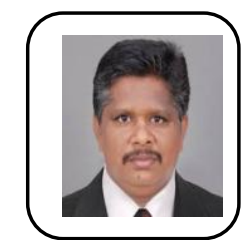

Dr.N.Rajini is a Professor in the Department of Mechanical Engineering, Kalasalingam Academy of Research and Education, Krishnankoil, Tamilnadu, India. His current area of research includes composite materials, tribology studies and bio composites $\mathrm{He}$ has published more than 100 numbers of papers in journal of national/international repute and presented a number of papers in various conferences/symposia in India and abroad. He is presently guiding a number of master/doctoral research scholars.

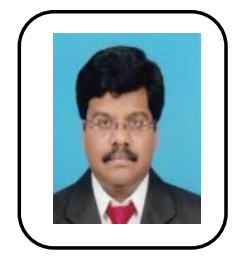

Dr.J.T.Winowlin Jappes is a Senior Professor in the Department of Mechanical Engineering, Kalasalingam Academy of Research and Education, Krishnankoil, Tamilnadu, India. He has more than 18 years of experience in teaching and research. His current area of research includes composite materials, surface coatings and bio composites He has published a number of papers in journal of national/international repute and presented a number of papers in various conferences/symposia in India and abroad. He is presently guiding a number of master/doctoral research scholars. 